\title{
Phenoxybenzamine treatment is insufficient to prevent spasm in the radial artery: The effect of other vasodilators
}

\author{
Alan R. Conant, $\mathrm{PhD}^{\mathrm{a}, \mathrm{b}}$ \\ Michael J. Shackcloth, FRCS ${ }^{a}$ \\ Aung Y. 0o, FRCS (CTh) ${ }^{a}$ \\ Michael R. Chester, MRCP, MDa \\ Alec W. M. Simpson, DPhil ${ }^{\mathrm{b}}$ \\ Walid C. Dihmis, FRCS (CTh) ${ }^{\text {a }}$
}

From the Cardiothoracic Centre, ${ }^{\mathrm{a}}$ Liverpool NHS Trust and Department Human Anatomy and Cell Biology, ${ }^{\text {b }}$ University of Liverpool, New Medical School, Liverpool, United Kingdom.

Funded by the Cardiothoracic Centre, Liverpool NHS Trust, Liverpool, United Kingdom.

Received for publication Sept 24, 2002; revisions requested Oct 25, 2002; revisions received Nov 8, 2002; accepted for publication Nov 11, 2002.

Address for reprints: Alan Conant, $\mathrm{PhD}$, The Cardiothoracic Centre, Liverpool NHS Trust, Thomas Drive, Liverpool L14 3PE, United Kingdom (E-mail: Alan.Conant@ ctc.NHS.uk).

J Thorac Cardiovasc Surg 2003;126:448-54

Copyright $(\underset{0}{ } 2003$ by The American Association for Thoracic Surgery

$0022-5223 / 2003 \$ 30.00+0$

doi:10.1016/S0022-5223(03)00388-X

Objectives: After its reintroduction as an arterial graft in coronary artery surgery, the radial artery is now established as an alternative arterial conduit, with good early and midterm patency. However, because of the concern about its vasospasticity, numerous vasodilator strategies have been used. Recently the use of the irreversible $\alpha$-adrenergic antagonist phenoxybenzamine has been proposed. Although this treatment is effective in eliminating the vasoconstriction mediated by noradrenaline, the contribution of other circulating vasoconstrictors to vasospasm could be as important. This study investigates the response of radial arteries treated with phenoxybenzamine to vasoconstrictor stimuli and possible preventative strategies.

Methods: In vitro, sections of radial artery, pretreated with phenoxybenzamine after harvesting, were stimulated with maximal concentrations of the vasoconstrictors noradrenaline, vasopressin, angiotensin $\mathrm{II}, \mathrm{KCl}$, and endothelin-1. In matched segments of artery, vasoconstrictor responses were recorded in the presence of diltiazem, glyceryl trinitrate, and papaverine and compared with phenoxybenzamine-treated samples.

Results: Phenoxybenzamine-treated radial artery failed to respond to noradrenaline but did respond to vasopressin, angiotensin II, endothelin-1, and $\mathrm{KCl}$. Diltiazem was largely ineffective against contractile stimuli apart from $\mathrm{KCl}$. Glyceryl trinitrate and papaverine significantly reduced responses to all of the vasoconstrictors tested.

Conclusion: In phenoxybenzamine-treated sections of radial artery, circulating vasoconstrictor agonists may still contribute to the induction of spasm. Additional vasodilator strategies may be required to completely prevent vasospasm.

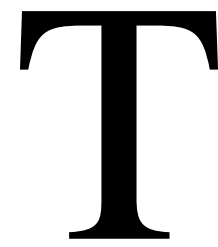

here is increasing evidence that the use of arterial grafts in coronary artery bypass surgery results in improved patency rates. The radial artery was first suggested by Carpentier and colleagues ${ }^{1}$ in 1973, but its use was soon abandoned because of unacceptably high early graft failure attributed to spontaneous contraction or spasm. However, further analysis at 15 years demonstrated that some of the grafts were disease-free and patent. ${ }^{2}$ This prompted a reevaluation of the radial artery as a potential conduit for bypass surgery. So far the results from midterm angiographic studies have demonstrated patency rates of radial artery grafts superior to the saphenous vein and almost as good as the internal thoracic artery. ${ }^{3-6}$ Thus, there has been an increase in the use of the radial artery in coronary artery bypass surgery.

Unfortunately spasm has been recorded in 4 to $10 \%$ of radial artery grafts immediately after the operation and may be even higher as nonacute cases of spasm may go undetected. ${ }^{2,5,6}$ The radial artery is particularly prone to spasm due to its muscular nature and large medial cross-sectional area as compared with the internal 
thoracic artery. ${ }^{7,8}$ Improvements in surgical technique and handling, whereby the radial artery is removed as a pedicle, have reduced the incidence of vasospasm. ${ }^{2}$ In addition, various vasodilator strategies have been proposed, including phosphodiesterase inhibitors, such as papaverine, amrinone, and milrinone, and glyceryl trinitrate (nitroglycerine) and other nitrovasodilators and L-type $\mathrm{Ca}^{2+}$ channel blockers, such as diltiazem, verapamil, and nicardipine. ${ }^{9}$ These have been used both alone and in combination but all have the drawback that the effect is rapidly removed by the circulation. Recently the use of the $\alpha$-adrenoceptor antagonist phenoxybenzamine has been proposed as an antispasmodic agent. ${ }^{10}$ Phenoxybenzamine binds irreversibly to the $\alpha_{1^{-}}$ adrenoceptor, the dominant adrenoceptor in the radial artery, ${ }^{11}$ and thus treatment with this compound renders the graft insensitive to the increased levels of catecholamines present in the circulation postoperatively. ${ }^{10}$ Phenoxybenzamine has been suggested as the sole prophylactic strategy for the prevention of spasm in the radial artery. However, the levels of several other vasoconstrictors are also increased as a result of surgery, and their contribution to the development of spasm should not be overlooked. ${ }^{12}$ Phenoxybenzamine also reacts irreversibly with calmodulin, the protein that integrates the rise in cellular calcium with contraction, albeit with a lower affinity than its interaction with the $\alpha$-adrenoceptor. ${ }^{13}$ We therefore considered establishing whether the radial artery treated with phenoxybenzamine was still capable of responding to other vasoconstrictors. To determine whether there is a case for the use of additional vasodilator strategies in phenoxybenzaminetreated radial artery, we have studied the response of phenoxybenzamine-treated sections of radial artery to depolarization, induced by $\mathrm{KCl}$, and to the vasoconstrictors vasopressin, angiotensin II, and endothelin-1, as well as to noradrenaline.

We investigated the 3 prophylactic strategies commonly used to prevent spasm in the radial artery-nitrovasodilators, calcium channel antagonists, and phosphodiesterase inhibitors-on sections of radial artery pretreated with phenoxybenzamine.

\section{Methods}

\section{Materials and Solutions}

Organ bath contraction studies were carried out in oxygenated HEPES-buffered-saline (HBS) solution composed of: $\mathrm{NaCl}, 145$ $\mathrm{mmol} / \mathrm{L} ; \mathrm{KCl}, 2.5 \mathrm{mmol} / \mathrm{L} ; \mathrm{Na}_{2} \mathrm{HPO}_{4}, 1 \mathrm{mmol} / \mathrm{L} ; \mathrm{MgSO}_{4}, 1$ $\mathrm{mmol} / \mathrm{L}$; HEPES, $10 \mathrm{mmol} / \mathrm{L}$; D-glucose, $10 \mathrm{mmol} / \mathrm{L} ; \mathrm{CaCl}_{2}, 1$ $\mathrm{mmol} / \mathrm{L} ; \mathrm{pH} 7.4$ at $37^{\circ} \mathrm{C}$. Hanks balanced salt solution (HBSS) containing $4 \mathrm{mmol} / \mathrm{L} \mathrm{NaHCO}_{3}$ was made up from powder and was sterile-filtered before storage at $4^{\circ} \mathrm{C}$ until use. The following reagents were obtained from the following companies: Dulbecco's modified Eagle medium and HBSS from Life Technologies (Paisley, Scotland); glyceryl trinitrate solution (nitroglycerine) and papaverine solution from DBL (Warwick, United Kingdom) and
Martindale Pharmaceuticals (Romford, United Kingdom); phenoxybenzamine solution from Goldshield Pharmaceuticals Ltd, (Croydon, United Kingdom); diltiazem, arg-vasopressin, angiotensin II, and endothelin-1 from Sigma Chemicals (Poole, United Kingdom). Fresh diltiazem stock solutions were made up before each experiment. All other chemicals and reagents from Merck Ltd (Poole, United Kingdom).

\section{Sample Preparation for Surgery}

Sections of radial artery, surplus to coronary artery bypass surgery, were collected from theater with fully informed patient consent and local ethical committee approval. In theater, radial arteries were treated with either phenoxybenzamine $(1 \mathrm{mg} / \mathrm{mL} ; 3 \mathrm{mmol} / \mathrm{L})$ in heparinized whole blood or papaverine $(0.6 \mathrm{mg} / \mathrm{mL} ; 1.6$ $\mathrm{mmol} / \mathrm{L}$ ) in saline solution, depending on the protocol of the surgeon. Samples of artery used for research were transported in ice-cold Dulbecco's modified Eagle medium to the research laboratory.

All phenoxybenzamine-treated samples remained insensitive to applications of noradrenaline for the duration of our experiments and no further application of phenoxybenzamine was applied.

\section{Organ Bath Contraction Studies}

Samples of artery were transferred to warmed $\left(37^{\circ} \mathrm{C}\right) \mathrm{HBSS}$, trimmed of connective tissue, and cut into 2- to 3-mm rings with a scalpel. The rings were mounted in $25 \mathrm{~mL}$ of HBS between 2 fine wire stirrups connected to a force transducer and changes in isometric force were recorded on a Lectromed 5220 medium gain amplifier, connected to a Lectromed MT6 chart recorder (Lectromed UK Ltd, Letchworth, Hertfordshire, United Kingdom). Each ring was stretched to a tension at 30 milli-Newtons $(\mathrm{mN})$ for 1 hour, after which tension was adjusted to $10 \mathrm{mN}$ and the rings left for a further 30 minutes before the addition of agonists. All rings were stimulated with $60 \mathrm{mmol} / \mathrm{L}$ of $\mathrm{KCl}$ before testing with other vasoconstrictors and only rings that responded to $\mathrm{KCl}$ were used for further experimentation. The vasoconstriction induced by maximal concentrations of vasoconstrictors was examined in the presence of 3 vasodilator strategies; phosphodiesterase inhibitors, nitrates, and calcium channel blockers. Maximal concentrations of agonists were obtained from previously published experimentation. $^{8,14,15}$ All data were collected from samples of radial artery collected from at least 3 separate patients, where " $n$ " refers to the number of patients studied and are presented as mean \pm SEM. Agonist responses in the presence of vasodilator were paired with responses in the absence of vasodilator. Paired rings were taken from the same sample of tissue. An initial $\mathrm{KCl}$ response was used to control for variation in contractility between rings from the same patient. This protocol was adopted to avoid desensitization due to repeated agonist additions. Statistical analysis was carried out using a paired $t$-test $(P<.05)$. Rings were pretreated with vasodilators for 5 minutes before the agonist addition and during the agonist response.

\section{Results \\ Study Samples}

Radial artery segments for the organ chamber studies were taken from 28 patients undergoing coronary artery bypass 


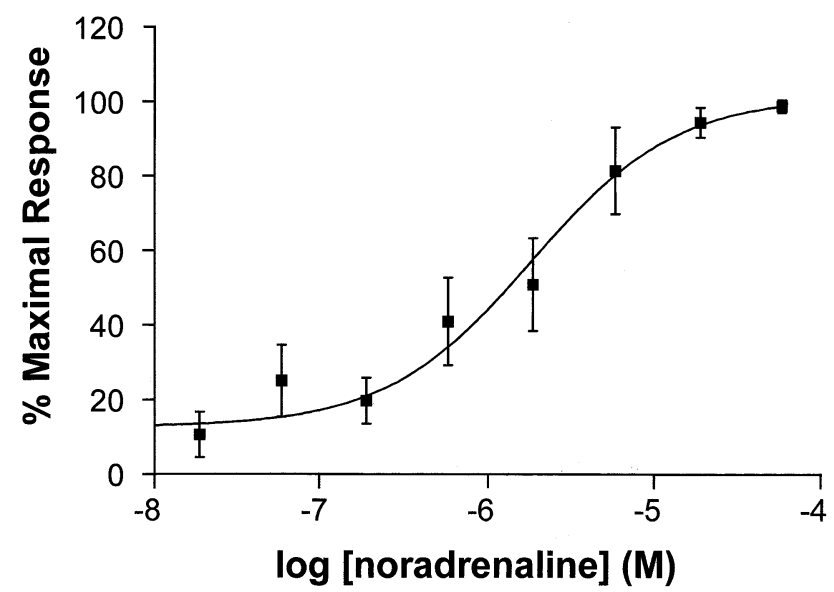

Figure 1. Mean concentration $\left(-\log _{10} \mathrm{~mol} / \mathrm{L}\right.$ ) contraction (percentage of maximal noradrenaline contraction) curve for noradrenaline in the human radial artery not treated with phenoxybenzamine in theater. Symbols represent data averaged from a group of rings (taken from 6 patients). Vertical error bars are 1 SEM values.

grafting. For samples treated with phenoxybenzamine in theater, there were 22 patients with a mean age of $62 \pm 2$ years. To characterize the response to noradrenaline in our organ bath, samples were also obtained from other surgeons not using phenoxybenzamine treatment. These samples were treated with papaverine in theater and were taken from 6 patients with a mean age of $61 \pm 4$ years. These samples were used as controls not treated with phenoxybenzamine.

\section{Response to Noradrenaline in Phenoxybenzamine- Treated Arteries}

To examine the effectiveness of phenoxybenzamine treatment on the noradrenaline response in the radial artery, the response to noradrenaline in sections of radial artery not treated with phenoxybenzamine in theater were compared with responses in phenoxybenzamine-treated radial arteries. Arterial sections not treated with phenoxybenzamine responded to noradrenaline with a concentration-dependent increase in vascular tension. Maximal tension was recorded at $20 \mu \mathrm{mol} / \mathrm{L}$ giving a value of $34.0 \pm 1.9 \mathrm{mN}$ and a median effective concentration $\left(\mathrm{EC}_{50}\right)$ of $1.8 \pm 0.6 \mu \mathrm{mol} / \mathrm{L}(\mathrm{n}=6$; Figure 1). At $2 \mu \mathrm{mol} / \mathrm{L}$ noradrenaline sections of radial artery not treated with phenoxybenzamine responded with an increase in tension from $13.0 \pm 0.6 \mathrm{mN}$ to $31.8 \pm 2.1$ $\mathrm{mN}(\mathrm{n}=6$; Figure $2, A)$. In contrast, phenoxybenzaminetreated sections of radial artery $(n=22)$ failed to respond to additions of either 2 or $20 \mu \mathrm{mol} / \mathrm{L}$ noradrenaline, when tested 4 to 5 hours after the initial treatment (Figure 2,B). This is consistent with a complete and irreversible blockade of the $\alpha$-adrenergic receptors.
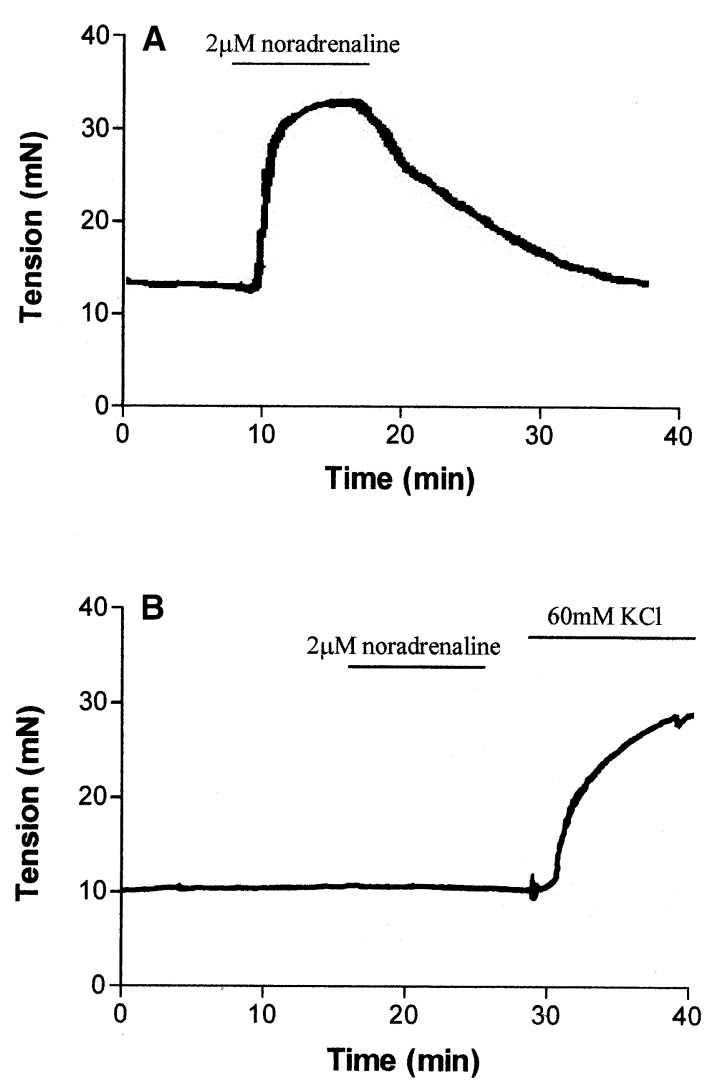

Figure 2. Representative traces showing force induced in the presence of $2 \mu \mathrm{mol} / \mathrm{L}$ noradrenaline in rings of human radial artery (A) not treated or (B) treated with phenoxybenzamine. Phenoxybenzamine-treated arteries were further stimulated with $60 \mathrm{mmol} / \mathrm{L} \mathrm{KCl}$ to demonstrate functional contractility. The presence of the vasoconstrictor stimulus in the bath solution is indicated by the horizontal bar. The responses were terminated by 2 changes of media.

\section{Responses to Vasoconstrictors in Phenoxybenzamine- Treated Arteries}

To examine the effect of phenoxybenzamine on voltageoperated calcium channels, tension concentration response curves were obtained for isomolar $\mathrm{KCl}$ additions in phenoxybenzamine-treated arteries. $\mathrm{KCl}$ gave an $\mathrm{EC}_{50}$ of 25.2 $\pm 3.6 \mathrm{mmol} / \mathrm{L}$ and maximal response of $33.0 \pm 2.4 \mathrm{mN}(\mathrm{n}$ $=3$ ). To determine whether the radial artery remained responsive to other vasoconstrictors, their effects on contractility were examined. Phenoxybenzamine-treated rings of radial artery with a basal tension of $9.8 \pm 2.3 \mathrm{mN}(\mathrm{n}=$ 22) responded to $100 \mathrm{nmol} / \mathrm{L}$ vasopressin, $100 \mathrm{nmol} / \mathrm{L}$ angiotensin II, and $10 \mathrm{nmol} / \mathrm{L}$ endothelin- 1 with increases in tension to $26.7 \pm 2.1 \mathrm{mN}(\mathrm{n}=8), 27.9 \pm 2.0 \mathrm{mN}(\mathrm{n}=13)$, and $23.0 \pm 1.7 \mathrm{mN}(\mathrm{n}=5)$. Representative responses are shown in Figure 3. 

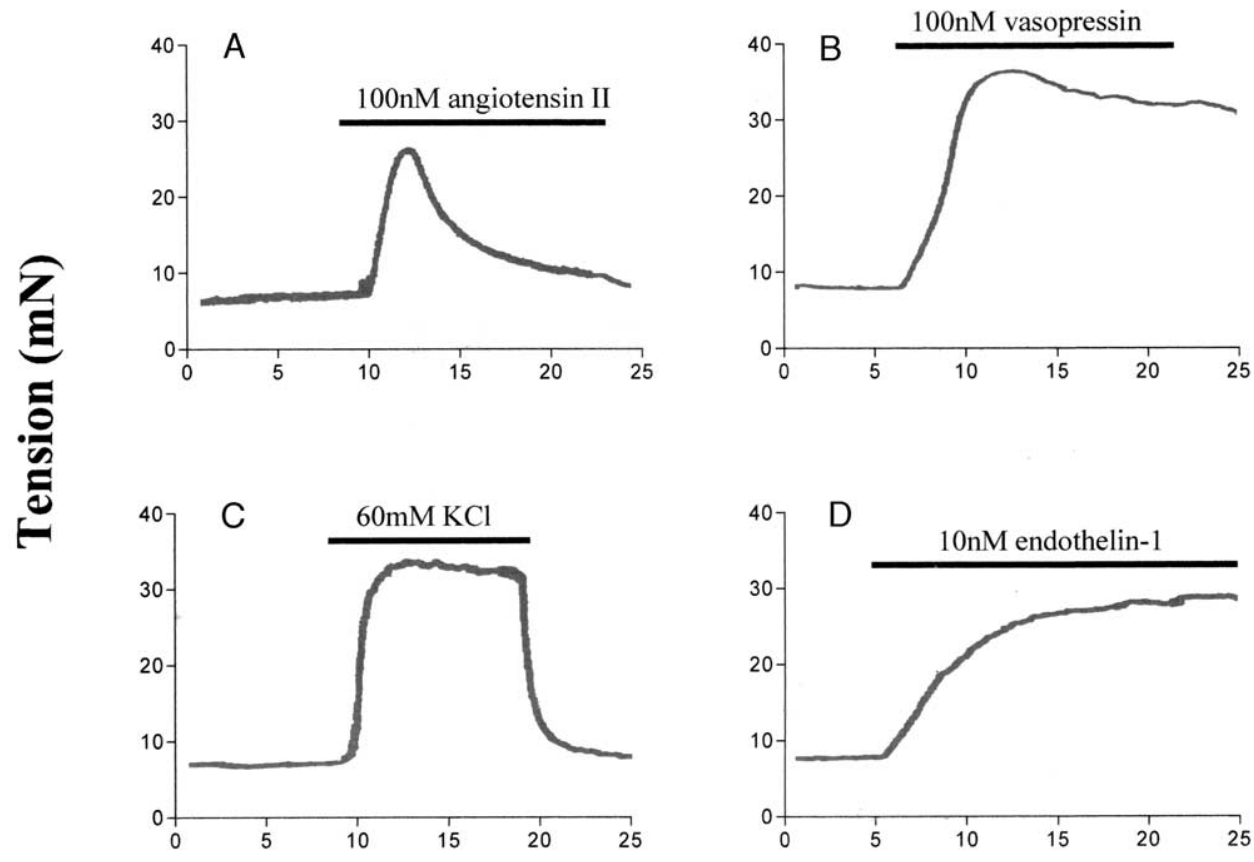

\section{Time (min)}

Figure 3. Representative traces showing force induced in phenoxybenzamine-treated rings of human radial artery by the application of (A) $100 \mathrm{nmol} / \mathrm{L}$ angiotensin II, (B) $100 \mathrm{nmol} / \mathrm{L}$ vasopressin, (C) $60 \mathrm{mmol} / \mathrm{L} \mathrm{KCl}$, and (D) $10 \mathrm{nmol} / \mathrm{L}$ endothelin-1. The presence of the agonist in the bath solution is indicated by the horizontal bar and the stimulus was removed by 2 changes of media.

\section{Reversal of Contraction in Phenoxybenzamine-Treated} Arteries

$\mathrm{KCl}$ and angiotensin II-induced contraction was rapidly reversed by washing. However, vasopressin and endothelin1-induced contraction remained sustained for upward of 25 minutes, even in the absence of agonist, and was not reversed by washing alone. The addition of glyceryl trinitrate completely reversed both vasopressin-induced contraction, in $13.2 \pm 1.3$ minutes $(\mathrm{n}=6)$, and endothelin 1-induced contraction in $8.9 \pm 2.1$ minutes $(n=4)$.

\section{The Effect of Vasodilator Strategies on}

\section{Vasoconstrictor Responses in Phenoxybenzamine-}

\section{Treated Radial Arteries}

Finally, the ability of vasoconstrictors to evoke contractile responses in the presence of various vasodilators was examined. Depolarization induced by $\mathrm{KCl}$ was significantly reduced by all of the treatments chosen (Figure 4, A). However, a measurable response was still obtained in the presence of diltiazem. Angiotensin II and vasopressin responses were significantly reduced by both papaverine and glyceryl trinitrate but not by diltiazem (Figure 4, $B$ and $C$ ). Endothelin-1 responses were significantly reduced by all treatments (Figure 4, D). Papaverine effectively abolished responses to $\mathrm{KCl}$, endothelin-1, and angiotensin II, where as glyceryl trinitrate completely abolished responses to only endothelin-1. Basal tension of $9.8 \pm 2.3 \mathrm{mN}(\mathrm{n}=22)$ was not significantly altered by any of the treatments tested. Therefore, glyceryltrinitrate and papaverine were effective against all of the vasoconstrictor stimuli chosen whereas diltiazem had only a limited use in preventing vasoconstriction.

\section{Discussion}

Since the initial report by Taggart and colleagues ${ }^{10}$ that treatment of the radial artery with phenoxybenzamine completely and irreversibly blocks the response to noradrenaline, it has been demonstrated that the effect persists for several days. ${ }^{16}$ This is because the smooth muscle cells, once treated with phenoxybenzamine, must resynthesize the $\alpha$-adrenergic receptors de novo before the response to noradrenaline can be reestablished. ${ }^{17}$ Therefore, pretreatment of the radial artery with phenoxybenzamine leaves the graft insensitive to the increased levels of noradrenaline circulating in the immediate postoperative period. This prophylactic strategy against noradrenaline-induced spasm may have a broader effect, as in addition to its properties as an 

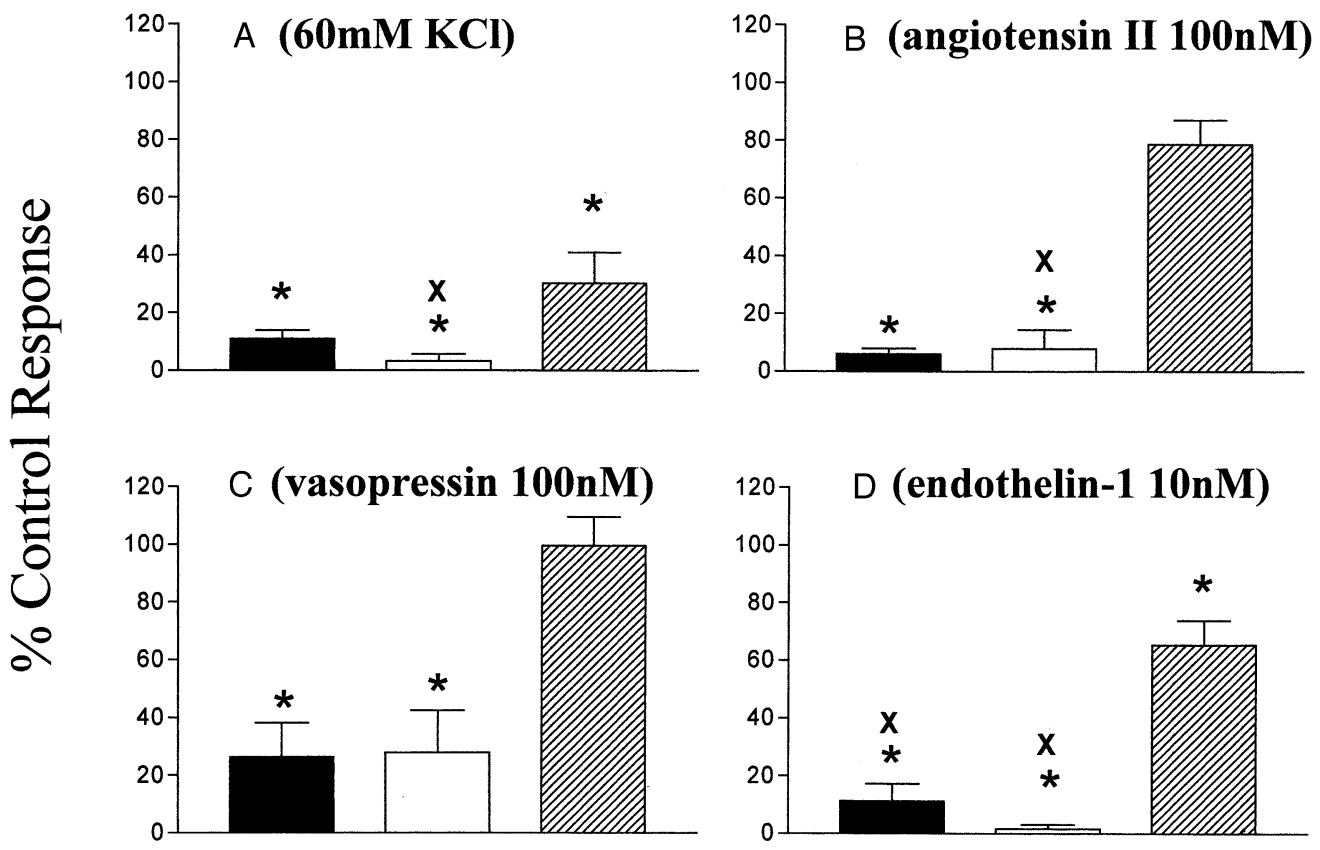

Figure 4. Mean force generated in phenoxybenzamine-treated rings of human radial artery by the application of (A) $60 \mathrm{mmol} / \mathrm{L} \mathrm{KCl,} \mathrm{(B)} 100 \mathrm{nmol} / \mathrm{L}$ angiotensin II, (C) $100 \mathrm{nmol} / \mathrm{L}$ vasopressin, and (D) $10 \mathrm{nmol} / \mathrm{L}$ endothelin-1. Data were collected in the presence of $0.5 \mathrm{mg} / \mathrm{mL}(2.2 \mathrm{mmol} / \mathrm{L})$ glyceryl trinitrate (filled bars), $0.5 \mathrm{mg} / \mathrm{mL}(1.3 \mathrm{mmol} / \mathrm{L}$ ) papaverine (open bars), or $4.5 \mu \mathrm{g} / \mathrm{mL}$ (10 $\mu \mathrm{mol} / \mathrm{L}$ ) diltiazem (striped bars). Data are presented as percentage of force generated in patient-matched rings without vasodilator. Vertical error bars are 1 SEM values. ${ }^{*}<<.05$ from patient-matched control values, ${ }^{x} \boldsymbol{P}<.05$ from prestimulus basal values.

irreversible adrenergic receptor antagonist, phenoxybenzamine also irreversibly antagonizes the intracellular protein calmodulin. ${ }^{13}$ Calmodulin integrates the vasoconstrictor-mediated increases in intracellular calcium to activation of the myosin light chain kinase, resulting in smooth muscle contraction. ${ }^{18}$ However, we found that when treated with phenoxybenzamine, which completely abolishes the response to noradrenaline, the radial artery still showed marked vasoconstriction to endothelin-1, angiotensin II, vasopressin, and depolarization induced by $\mathrm{KCl}$. Our results suggest that any interaction with calmodulin is unlikely to contribute to an antispasmodic action of phenoxybenzamine. This therefore warrants the continued development of vasodilator strategies for the radial artery.

After the reintroduction of the radial artery in coronary artery bypass grafting, the improved patency was partially attributed to the use of systemic diltiazem in the postoperative period. ${ }^{2}$ It has since been demonstrated that diltiazem has only a limited effect against $\mathrm{KCl}$ and other vasoconstrictors in the radial artery, at concentrations considered to be within the physiologic range. ${ }^{19,20}$ We selected a dose of diltiazem equivalent to a topical application routinely used in theater and sufficient to significantly inhibit $\mathrm{KCl}$-induced contraction. ${ }^{20} \mathrm{We}$ found that at $10 \mu \mathrm{mol} / \mathrm{L}$, diltiazem effectively reduced $\mathrm{KCl}$-induced contraction but could not re- producibly abolish it and failed to significantly influence the maximal response of the radial artery to vasopressin and angiotensin II. Although the response to endothelin-1 was reduced by diltiazem, there was still a substantial increase in tension.

In contrast to diltiazem, we found glyceryl trinitrate and papaverine to have a much broader inhibitory action against a variety of vasoconstrictor stimuli, blocking responses to angiotensin II, endothelin-1, vasopressin, and $\mathrm{KCl}$. This is not surprising as both of these compounds can antagonize the rise in smooth muscle cell calcium and act directly on the contractile apparatus. Glyceryl trinitrate increases smooth muscle nitric oxide. Nitric oxide inhibits receptorstimulated calcium release from intracellular stores and reduces calcium influx by hyperpolarizing the cell membrane or inhibiting the voltage-gated calcium channel. ${ }^{9,21}$ In addition, nitric oxide promotes calcium reuptake into the stores and calcium extrusion, as well as accelerating myosin light chain phosphorylation. ${ }^{9,22}$ This effectively means that glyceryl trinitrate opposes both agonist-mediated contraction and subsequent sensitization caused by the activation of Rho kinase. Papaverine acting predominantly as a type III phosphodiesterase inhibitor raises intracellular cyclic adenosine monophosphate, leading to activation of protein ki- 
nase A and inhibiting many of the processes antagonized by nitric oxide. ${ }^{9,22}$

In our study high doses corresponding to topical applications were used to evaluate the maximal effect obtainable. However, even at levels a thousandfold lower than those used in this study, glyceryl trinitrate has been shown to reduce the response to $\mathrm{KCl}$ and adrenaline by more than $60 \% .{ }^{19}$ A combination of nitrovasodilators, calcium channel antagonists, and phophodiesterase inhibitors may be additive, enhancing the efficacy of low doses of either treatment. ${ }^{23,24}$ Topical papaverine, however, may damage the endothelium ${ }^{16,24}$ and may sensitize the artery to vasoconstrictors ${ }^{25}$; therefore, the use of other phosphodiesterase inhibitors such as milrinone may be preferable and may give similar results. ${ }^{26}$ All of these treatment strategies require repeated administration to maintain their beneficial effects. In contrast, treatment with phenoxybenzamine is irreversible and therefore requires a single topical application administered solely to the grafted artery. An alternative to a mixed vasodilator strategy may be the development of an irreversible treatment targeted to one of the signaling pathways, linking a rise in intracellular calcium to contraction.

Cardiopulmonary bypass may cause a profound drop in systemic vascular resistance due to severe vasodilatation, which results in a low blood pressure in the presence of a high cardiac output (systemic inflammatory syndrome). This can be treated with the infusion of either noradrenaline or vasopressin. ${ }^{27}$ As has been demonstrated, pretreatment with phenoxybenzamine will prevent spasm of the radial artery in the presence of noradrenaline. The use of vasopressin would result in rapid and sustained contraction of the radial artery, which would not be easily removed by the circulation. Thus phenoxybenzamine pretreatment would prevent the spasm caused by noradrenaline used to treat systemic inflammatory syndrome without compromising the radial artery graft. However, the use of topical phenoxybenzamine as the sole strategy to prevent spasm of the radial artery is not sufficient. The phenoxybenzamine-treated radial artery is still capable of substantial contraction in the presence of other circulating vasoconstrictors. Nitrates or phosphodiesterase inhibitors may still have a major role to play in the prevention and treatment of radial artery spasm.

In conclusion, we would recommend that phenoxybenzamine should not be used as a sole agent in the prevention of radial artery spasm after coronary artery bypass graft surgery. The use of nitrates, phosphodiesterase inhibitors, or calcium channel blockers may offer further protection against spasm. There may be a role for a single compound that will combine all these effects in preventing and treating spasm in this promising bypass conduit.

We are grateful to the surgeons and theater staff at the chest theaters (Cardiothoracic Centre) for the provision of samples of radial artery. We also thank Dr Susan Coker, Department of
Pharmacology, University of Liverpool, for the use of the organ bath.

\section{References}

1. Carpentier A, Guermonprez JL, Deloche A, Frechette C, DuBost C. The aorta-to-coronary radial artery bypass graft. A technique avoiding pathological changes in grafts. Ann Thorac Surg. 1973;16:111-21.

2. Acar C, Jebara VA, Portoghese M, et al. Revival of the radial artery for coronary-artery bypass-grafting. Ann Thorac Surg. 1992;54:652-60.

3. Acar C, Ramsheyi A, Pagny JY, et al. The radial artery for coronary artery bypass grafting: clinical and angiographic results at five years. J Thorac Cardiovasc Surg. 1998;116:981-8.

4. Calafiore AM, Di Mauro M, D’Alessandro S, et al. Revascularization of the lateral wall: long-term angiographic and clinical results of radial artery versus right internal thoracic artery grafting. J Thorac Cardiovasc Surg. 2002;123:225-31.

5. Possati G, Gaudino M, Alessandrini F, et al. Midterm clinical and angiographic results of radial artery grafts used for myocardial revascularization. J Thorac Cardiovasc Surg. 1998;116:1015-21.

6. Tatoulis J, Royse AG, Buxton BF, et al. The radial artery in coronary surgery: a 5-year experience-clinical and angiographic results. Ann Thorac Surg. 2002;73:143-7.

7. Acar C, Jebara VA, Portoghese M, et al. Comparative anatomy and histology of the radial artery and the internal thoracic artery-implication for coronary-artery bypass. Surg Radiol Anat. 1991;13:283-8.

8. He GW, Yang CQ. Comparison among arterial grafts and coronaryartery-an attempt at functional classification. J Thorac Cardiovasc Surg. 1995;109:707-15.

9. Rosenfeldt FL, He GW, Buxton BF, Angus JA. Pharmacology of coronary artery bypass grafts. Ann Thorac Surg. 1999;67:878-88.

10. Taggart DP, Dipp M, Mussa S, Nye PCG. Phenoxybenzamine prevents spasm in radial artery conduits for coronary artery bypass grafting. J Thorac Cardiovasc Surg. 2000;120:815-7.

11. He GW, Yang CQ. Characteristics of adrenoceptors in the human radial artery: clinical implications. J Thorac Cardiovasc Surg. 1998; 115:1136-41.

12. Downing SW, Edmunds LH. Release of vasoactive substances during cardiopulmonary bypass. Ann Thorac Surg. 1992;54:1236-43.

13. Ning YM, Sanchez ER. Evidence for a functional interaction between calmodulin and the glucocorticoid receptor. Biochem Biophys Res Commun. 1995;208:48-54.

14. He GW, Yang CQ. Radial artery has higher receptor-mediated contractility but similar endothelial function compared with mammary artery. Ann Thorac Surg. 1997;63:1346-52.

15. Wei W, Floten HS, He GW. Interaction between vasodilators and vasopressin in internal mammary artery and clinical significance. Ann Thorac Surg. 2002;73:516-22.

16. Dipp MA, Nye PCG, Taggart DP. Phenoxybenzamine is more effective and less harmful than papaverine in the prevention of radial artery vasospasm. Eur J Cardiothorac Surg. 2001;19:482-6.

17. Hamilton CA, Dalrymple HW, Reid JL, Sumner DJ. The recovery of alpha-adrenoceptor function and binding-sites after phenoxybenzamine-an index of receptor turnover. Naunyn-Schmiedebergs Arch Pharmacol. 1984;325:34-41.

18. Orallo F. Regulation of cytosolic calcium levels in vascular smooth muscle. Pharmacol Ther. 1996;69:153-71.

19. Cable DG, Caccitolo JA, Pearson PJ, et al. New approaches to prevention and treatment of radial artery graft vasospasm. Circulation. 1998;98:II15-21.

20. He GW, Yang CQ. Comparative study on calcium channel antagonists in the human radial artery: clinical implications. J Thorac Cardiovasc Surg. 2000;119:94-100.

21. Lincoln TM, Komalavilas P. Cyclic GMP-mediated signaling mechanisms in smooth muscle. In: Ignarro LJ, editor. Nitric oxide biology and pathobiology. London: Academic Press; 2000. p. 401-25.

22. Polson JB, Strada SJ. Cyclic nucleotide phosphodiesterases and vascular smooth muscle. Ann Rev Pharmacol Toxicol. 1996;36:403-27.

23. He GW, Yang CQ, Gately $\mathrm{H}$, et al. Potential greater than additive vasorelaxant actions of milrinone and nitroglycerin on human conduit arteries. Br J Clin Pharmacol. 1996;41:101-7. 
24. He GW. Verapamil plus nitroglycerin solution maximally preserves endothelial function of the radial artery: comparison with papaverine solution. J Thorac Cardiovasc Surg. 1998;115:1321-7.

25. Tatoulis J, Jiang GC, Moffatt JD, Cocks TM. Storage of radial artery grafts in blood increases vessel reactivity to vasoconstrictors in vitro. Ann Thorac Surg. 1999;68:2191-5.
26. He GW, Yang CQ. Vasorelaxant effect of phosphodiesterase-inhibitor milrinone in the human radial artery used as coronary bypass graft. J Thorac Cardiovasc Surg. 2000;119:1039-45.

27. Overand PT, Teply JF. Vasopressin for the treatment of refractory hypotension after cardiopulmonary bypass. Anesth Analg. 1998;86: 1207-9.

Access to The Journal of Thoracic and Cardiovascular Surgery Online is reserved for print subscribers!

Full-text access to The Journal of Thoracic and Cardiovascular Surgery Online is available for all print subscribers. To activate your individual online subscription, please visit The Journal of Thoracic and Cardiovascular Surgery Online, point your browser to http://www.mosby.com/jtcvs, follow the prompts to activate your online access, and follow the instructions. To activate your account, you will need your subscriber account number, which you can find on your mailing label (note: the number of digits in your subscriber account number varies from 6 to 10 ). See the example below in which the subscriber account number has been circled:

\section{Sample mailing label}

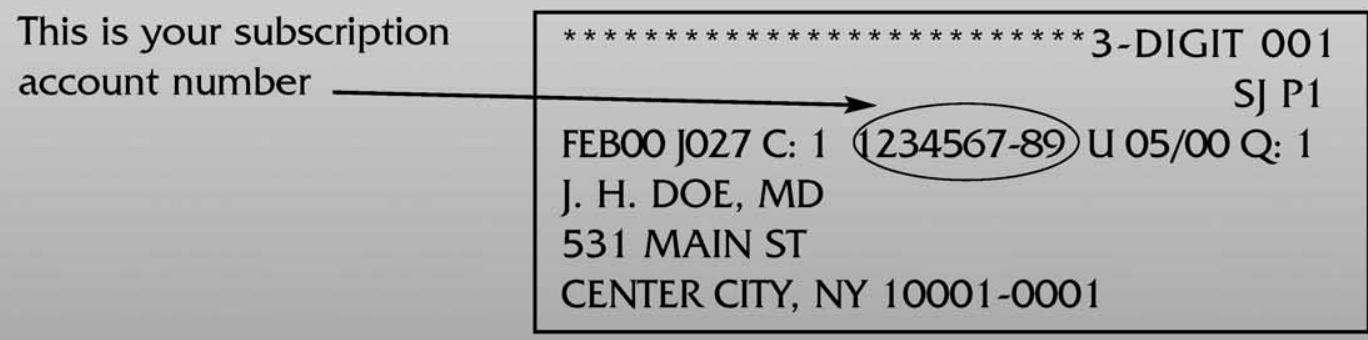

Personal subscriptions to The Journal of Thoracic and Cardiovascular Surgery Online are for individual use only and may not be transferred. Use of The Journal of Thoracic and Cardiovascular Surgery Online is subject to agreement to the terms and conditions as indicated online. 